\title{
A randomized, controlled trial to test the effectiveness of a glaucoma patient navigator to improve appointment adherence
}

This article was published in the following Dove Press journal:

Patient Preference and Adherence

8 September 2016

Number of times this article has been viewed

\author{
Lisa A Hark \\ Deiana M Johnson \\ Giuliana Berardi \\ Neal S Patel \\ Lichuan Zeng \\ Yang Dai \\ Eileen L Mayro \\ Michael Waisbourd \\ L Jay Katz
}

On behalf of the Glaucoma

Research Group

Wills Eye Hospital Glaucoma Research Center, Philadelphia, PA, USA
Correspondence: Lisa A Hark Department of Research, Glaucoma Research Center, Wills Eye Hospital, 840 Walnut Street, Suite 802, Philadelphia, PA 19107, USA

Tel +l 2159283045

$\mathrm{Fax}+\mathrm{I} 2159289085$

Email lhark@willseye.org
Purpose: Patients with glaucoma who do not keep their follow-up eye care appointments are at risk for developing more severe ocular disease. The primary aim of the current study was to evaluate whether the use of a patient navigator altered adherence to follow-up eye care appointments in community-versus office-based settings.

Patients and methods: Patients diagnosed with a glaucoma-related condition following a comprehensive eye examination at 43 community sites in Philadelphia, PA, USA, were enrolled in this prospective, randomized, controlled trial. Patients were randomized into three groups for a 1-year period: Group 1 (G1) received follow-up eye care in a community-based setting with assistance from a patient navigator; Group $2(\mathrm{G} 2)$ received follow-up eye care in an office-based setting with assistance from a patient navigator; and Group 3 (G3) received follow-up eye care in an office-based setting without a patient navigator (usual care). Adherence rates were compared among these three groups using a chi-squared test at a significance level of 0.05 .

Results: A total of 155 patients with glaucoma-related diagnoses were enrolled. The mean age ( \pm standard deviation) was $71.2( \pm 10.0)$ years. Patients were predominantly female $(65.8 \%$, $\mathrm{n}=102 / 155)$ and African-American $(71.6 \%, \mathrm{n}=111 / 155)$. The mean ( \pm standard deviation) number of follow-up visits during the 1-year study period was $1.3( \pm 1.3)$ for $G 1,1.6( \pm 1.3)$ for $G 2$, and $1.3( \pm 1.1)$ for $\mathrm{G} 3(P=0.48)$. Appointment adherence, defined as attendance of $\geq 1$ follow-up visit, was $69.8 \%(\mathrm{n}=37 / 53)$ for $\mathrm{G} 1,82.5 \%(\mathrm{n}=47 / 57)$ for $\mathrm{G} 2$, and $73.3 \%(\mathrm{n}=33 / 45)$ for $\mathrm{G} 3$, $(P=0.28)$. Sub-analysis of adherence rates for patients who attended $\geq 2$ follow-up visits were $91.3 \%(n=21 / 23)$ for $\mathrm{G} 1,74.3 \%(\mathrm{n}=26 / 35)$ for $\mathrm{G} 2$, and $66.7 \%(\mathrm{n}=18 / 27)$ for $\mathrm{G} 3,(P=0.11)$.

Conclusion: Help from a patient navigator did not increase the likelihood of keeping $\geq 1$ follow-up appointment in an office-based setting. Adherence rates for follow-up appointments reached close to $70 \%$ or above in a self-selected patient population.

Keywords: patient navigator, appointment adherence, glaucoma, access to eye care, underserved population

\section{Introduction}

Glaucoma, a progressive optic neuropathy, is the leading cause of irreversible blindness worldwide and affects over 65 million Americans. ${ }^{1,2}$ Most people are unaware they have glaucoma in early stages. ${ }^{3,4}$ Appropriate treatment and follow-up eye care are crucial in preventing vision loss due to glaucoma, as treatment can prevent blindness..$^{3-7}$ While patient compliance is often difficult to identify precisely, studies have estimated nonadherence to follow-up eye appointments as high as $43 \%$ among those diagnosed with glaucoma who were prescribed intraocular pressurelowering eye drops. ${ }^{8,9}$ 
A wide range of risk factors for low adherence to follow-up eye examination appointments has been identified, including advanced age, African-American or Latino ethnicity, and diagnosis of depression. ${ }^{10-13}$ Other factors associated with poor follow-up adherence, especially among the underserved, include poor health literacy and difficulty navigating the complex healthcare system. ${ }^{11,12,14,15}$ In previous studies, patients self-reported that a lack of transportation, difficulty affording copayment, uncertainty of where to find an ophthalmologist, a busy schedule, fear of an ocular diagnosis, and fear of treatment were all barriers to obtaining regular glaucoma-related eye examinations..$^{3,8,9,11,12,14-16}$ Research has suggested many strategies to improve patient adherence, but one of the most promising options involves the addition of a dedicated healthcare worker to help and encourage patients to attend eye examination appointments..$^{2-4,17-19}$

The introduction of this third party, often referred to as a patient navigator, is an intervention directly aimed at reducing the most frequently reported barriers preventing patients from receiving optimal care. ${ }^{20}$ The patient navigator concept was first introduced in the 1990s by Dr Harold Freeman to help females obtain breast cancer screening. ${ }^{20,21}$ Patient navigation programs have been shown in several randomized, controlled trials to improve appointment adherence, initiation of treatment, and patients' quality of life..$^{21,22}$ Patient navigators have been utilized in a variety of medical fields with the navigators serving to help patients schedule doctor's appointments, determine insurance requirements, arrange transportation, make appointment reminder calls, and accompany patients to their appointments..$^{20-24}$ However, there is limited data on the use of a patient navigator in an ophthalmic patient population and its efficacy in improving follow-up adherence and preventing vision loss, particularly among patients diagnosed with glaucomatous diseases.

To determine the impact of a patient navigator on glaucoma eye care follow-up adherence, we initiated a 1-year prospective, randomized, controlled trial in an urban community setting versus office-based setting.

\section{Patients and methods Institutional review board approval}

This trial was approved by the Institutional Review Board of Wills Eye Hospital and conducted in accordance to the Declaration of Helsinki.

\section{Patient recruitment}

This study enrolled 155 patients who were diagnosed with suspected glaucomatous disease, anatomically narrow angle, or glaucoma. All patients were recruited from a prior community outreach initiative (Philadelphia Glaucoma Detection and Treatment Project), funded by the US Centers for Disease Control and Prevention. ${ }^{25,26}$ During this program, a total of 1,649 individuals at high-risk for eye disease were examined, diagnosed, and given treatment recommendations by an ophthalmologist at 43 community sites throughout the Philadelphia region. Of this group, 645 patients were diagnosed with glaucoma-related conditions and required additional follow-up; they were eligible to participate in the present study (Figure 1). Beginning in August 2014, these eligible patients were sent three recruitment letters and called up to six times over the course of 4 months by study coordinators. This communication also included educational messages

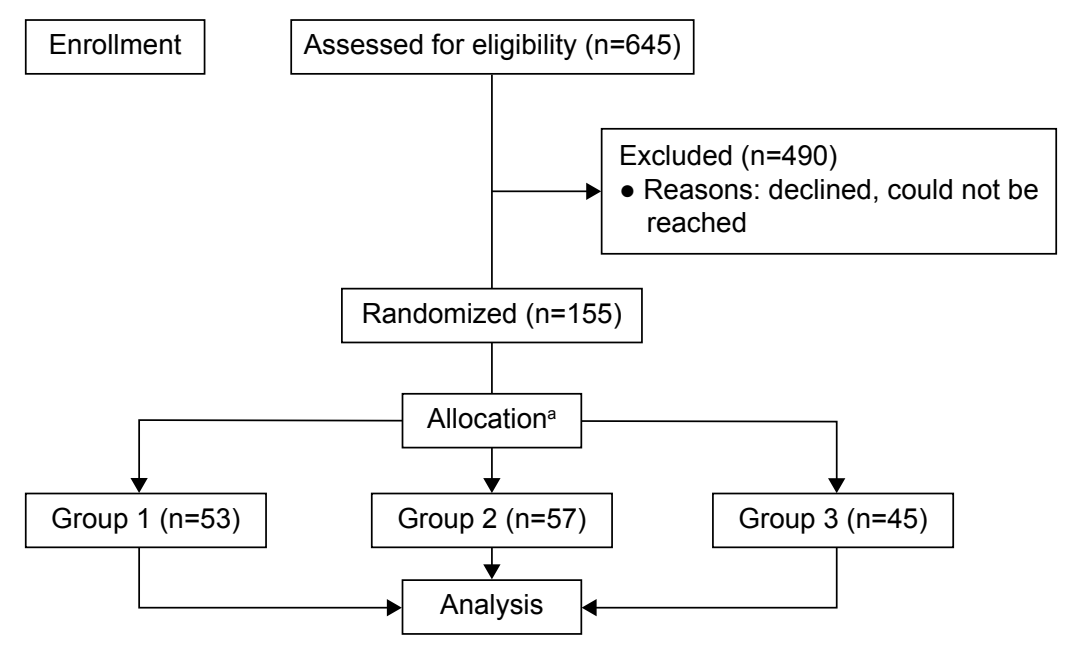

Figure I Flowchart of patients' recruitment and randomization.

Notes: Patients and providers were not masked; allocation ratio was $\sim$ : I:I, by site. Differences in sample sizes at each site result in different numbers of subjects in each group. 
about the importance of ongoing follow-up eye examinations once diagnosed with a glaucoma-related condition.

Eligible patients did not participate for a number of reasons. They were unreachable, because of either outdated information or unanswered voice mails. The remaining patients either opted out on their own or were unable to participate due to health or living situation. A small portion of patients were visiting other eye care providers or believed they did not have glaucoma.

\section{Study design}

Subjects were equally randomized into one of three groups for a 1-year period (Figure 1): Group 1 (G1) received follow-up eye care in a community-based setting with assistance from a patient navigator; Group 2 (G2) received follow-up eye care in an office-based setting with assistance from a patient navigator; and Group 3 (G3) received follow-up eye care in an office-based setting without a patient navigator (usual care).

Of the prior 43 community sites in the Philadelphia Glaucoma Detection and Treatment Project, four sites were selected for subjects randomized to G1 for follow-up eye care in a community-based setting with assistance from a patient navigator. In order to maximize patient accessibility, these four sites were chosen in different regions of Philadelphia. Wills Eye Hospital was used as the office-based site for patients randomized to $\mathrm{G} 2$ and $\mathrm{G} 3$.

Over the course of 1-year, subjects from all groups were offered a baseline eye examination and one or more follow-up visits depending on their diagnosis. Follow-up recommendations were based on the Practice Pattern Guidelines for Glaucoma from the American Academy of Ophthalmology (Table 1), but varied depending on the glaucoma specialists' clinical judgments. ${ }^{27}$

\section{Baseline visit and assessment measures}

Baseline eye examinations were conducted at all locations by an intervention team, consisting of an ophthalmologist, a mobile unit coordinator, two ophthalmic technicians, a study coordinator, a community health educator, and a patient navigator. A mobile unit was used to transport the entire team and all screening equipment to the community sites.

All subjects were formally enrolled in the study after obtaining written informed consent. All subjects received a comprehensive ophthalmic examination including: 1) ocular and medical history, 2) best corrected visual acuity measurement using Snellen eye charts (Precision Vision, La Salle, IL, USA), 3) slit-lamp biomicroscopy (Haag-Streit, Koeniz, Switzerland), 4) gonioscopy, 5) intraocular pressure measurement using Goldmann applanation tonometer (HaagStreit), 6) undilated optic nerve evaluation, and 7) visual field test using the Octopus visual field analyzer (Haag-Streit). Optic disc color photography and central corneal thickness measurements were documented if not available from prior records. An ophthalmologist reviewed the test results with each subject and provided a diagnosis, recommended treatment, and follow-up plan within 1-year based on recommended guidelines (Table 1).

During the baseline visit, the National Eye InstituteVisual Function Questionnaire-25 (NEI VFQ-25) was administered to all subjects to access barriers to eye care. ${ }^{28-30}$ Subjects also were given the Geriatric Depression Scale-15 (GDS-15), a validated 15-question assessment of depression in older adults that correlates with the severity of glaucoma. ${ }^{31,32}$ Complete results for both NEI VFQ-25 and GDS-15 are being published elsewhere.

\section{Follow-up visits/usual care}

Subjects who completed the baseline assessment and examination visit were scheduled for follow-up visits at one of the community sites or at Wills Eye Hospital, depending on their randomization. All subjects received a reminder phone call the day before their follow-up appointment. If the subject did not answer, a message was left on his or her phone. There was no charge or copay for any of the study visits.

Table I Recommended follow-up visits by diagnosis and treatment

\begin{tabular}{|c|c|c|c|c|}
\hline Diagnosis/treatment & $\begin{array}{l}\text { Baseline } \\
\text { visit }\end{array}$ & $\begin{array}{l}\text { 6-month } \\
\text { follow-up visit }\end{array}$ & $\begin{array}{l}\text { I 2-month } \\
\text { follow-up visit }\end{array}$ & $\begin{array}{l}\text { Total recommended } \\
\text { follow-up visits }\end{array}$ \\
\hline Glaucoma & $\checkmark$ & $\checkmark$ & $\checkmark$ & 2 \\
\hline $\begin{array}{l}\text { Glaucoma, treated with selective } \\
\text { laser trabeculoplasty }\end{array}$ & $\checkmark$ & $\checkmark$ & $\checkmark$ & 2 \\
\hline Glaucoma suspect & $\checkmark$ & & $\checkmark$ & $\mathrm{I}$ \\
\hline Anatomically narrow angle & $\checkmark$ & $\checkmark$ & $\checkmark$ & 2 \\
\hline $\begin{array}{c}\text { Anatomically narrow angle, treated } \\
\text { with laser peripheral iridotomy }\end{array}$ & $\checkmark$ & & $\checkmark$ & I \\
\hline
\end{tabular}

Note: Based on the American Academy of Ophthalmology, Preferred Practice Pattern Guidelines for Glaucoma. ${ }^{27}$ 
Follow-up visits consisted of an ocular and medical history review, an assessment of medication adherence, and a complete eye examination. Patients were given a brochure about glaucoma explaining the importance of regular eye examinations and treatment options. Subjects required a minimum of one follow-up visit within 1-year of their baseline visit regardless of their diagnosis or treatment plan.

All subjects received instructions on proper eyedrop administration and assistance with medication refill and adherence, if needed. For subjects without prescription drug coverage that could not afford their medications, study coordinators helped them to receive either discounted medications through GoodRx.com or free medication through the pharmaceutical companies' patient assistance programs. All subjects were called to confirm that they filled their prescription following study visits.

Glaucoma laser treatment (selective laser trabeculoplasty or laser peripheral iridotomy) was free of charge for all patients and performed by the ophthalmologist at all sites. If operating-room, nonlaser glaucoma surgery was recommended and a subject did not have insurance, a study coordinator would assist him or her to obtain the necessary health insurance. If a subject had health insurance that was not accepted at Wills Eye Hospital, a staff member would locate an ophthalmologist who accepted his or her insurance. In addition, staff members helped subjects with referrals to other nonglaucoma ophthalmology services, as needed.
Of the subjects who were non-English speakers, interpreters (who spoke primarily Spanish or Mandarin Chinese, but also occasionally French or Arabic) were provided to assist with recommended follow-up visits, medication refills, and laser therapy.

\section{Patient navigator/intervention}

Following the baseline visit, subjects in G1 (examined at community site) and G2 (examined at office-based site) were assisted by a patient navigator to identify barriers and improve appointment attendance. Two patient navigators were trained at the Wills Eye Hospital's Glaucoma Research Center on the potential barriers faced by subjects and the methods and resources to address these needs.

Patient navigators employed the "teach-back" method to ensure that subjects understood what was explained to them by having them repeat what they had just heard. Navigators resolved subjects' transportation barriers by helping subjects with their access to public transportation or door-to-door transportation provided by the Philadelphia regional transportation services, if needed. In addition, navigators provided parking reimbursements for subjects seen at the office-based Wills Eye Hospital site. Subjects in G1 and G2 also received a reminder letter before their scheduled appointment and a retention letter for any missed appointments, along with the appointment reminder phone call that all subject groups received (Table 2).

Table 2 Barriers to eye care addressed by the patient navigator

\begin{tabular}{|c|c|}
\hline Barrier to eye care & Approach to overcome barrier \\
\hline Reaching high-risk populations & $\begin{array}{l}\text { Community-based, targeted intervention performed near or at the residency of individuals } \\
\text { at risk or glaucoma. }\end{array}$ \\
\hline Lack of knowledge regarding risk & Educational programs/workshops prior to glaucoma examinations. \\
\hline Lack of trust & $\begin{array}{l}\text { Collaborating with trusted local community partners; establishing relationship with } \\
\text { community partners and patients. }\end{array}$ \\
\hline Lack of access to eye care provider & $\begin{array}{l}\text { Facilitating access by providing the examination at the community sites and providing names } \\
\text { of local ophthalmologists for follow-up. }\end{array}$ \\
\hline $\begin{array}{l}\text { Need for multiple follow-up visits once } \\
\text { glaucoma treatment is initiated }\end{array}$ & $\begin{array}{l}\text { Reducing the number of visits by offering laser treatment at the community site and treating } \\
\text { both eyes on the same day. }\end{array}$ \\
\hline Low rate of follow-up & $\begin{array}{l}\text { Reminding patients of follow-up appointments by letters and phone-calls; providing follow-up } \\
\text { appointments in the community setting. }\end{array}$ \\
\hline $\begin{array}{l}\text { Lack of single test to diagnose } \\
\text { glaucoma }\end{array}$ & $\begin{array}{l}\text { Establishing detection system that includes intraocular pressure, corneal pachymetry, visual } \\
\text { field, gonioscopy, and slit-lamp examination in one visit. }\end{array}$ \\
\hline $\begin{array}{l}\text { Poor adherence with using glaucoma } \\
\text { medication }\end{array}$ & $\begin{array}{l}\text { Offering selective laser trabeculoplasty as a first-line treatment as an alternative for eye } \\
\text { drops for primary open-angle glaucoma. }\end{array}$ \\
\hline Language & Translated educational material; medical interpreters on site. \\
\hline Transportation & $\begin{array}{l}\text { Transporting the intervention team and equipment to the community; community and senior } \\
\text { center managed transportation. }\end{array}$ \\
\hline Lack of medical insurance & $\begin{array}{l}\text { Assistance with application to charity care and referral to city health centers that provide eye } \\
\text { care for uninsured residents of Philadelphia. }\end{array}$ \\
\hline $\begin{array}{l}\text { Cost of eye care for office visits and } \\
\text { treatments }\end{array}$ & $\begin{array}{l}\text { Provided comprehensive eye examination and laser treatment at no cost to the patient as } \\
\text { part of the demonstrational project. }\end{array}$ \\
\hline
\end{tabular}

Note: Wills Eye Hospital Glaucoma Research Center. 2016. Used with permission. 


\section{Patient remuneration}

All subjects received a US\$20.00 gift card from a local pharmacy for study enrollment and an additional US $\$ 10.00$ gift card after completion of the final visit.

\section{Data collection}

FileMaker Pro 11 (FileMaker Inc., Santa Clara, CA, USA), which automatically generates unique participant identifications, was used to track follow-up appointment adherence and scheduling. Specifically, the number of follow-up visits that each subject scheduled, attended, rescheduled, cancelled, and missed were recorded. Additionally, all attempts to contact each subject and reasons for cancellations were documented. Information within FileMaker Pro was exported into Statistical Package for Social Science (SPSS, version 19, IBM Corporation, Armonk, NY, USA) for subject data analysis. The results of NEI VFQ-25 and GDS-15 were also exported into SPSS by the data manager.

\section{Randomization and statistical analysis}

Subjects were randomized by a biostatistician who had no involvement in delivering any intervention using cluster randomization so that sites were randomized to one of the three groups in a 1:1:1 ratio. Due to differences in sample sizes by site, the number of subjects in each group was not the same. The original sample size goal of 345 randomized subjects provided $90 \%$ power to detect a difference in follow-up rates between any two groups of $25 \%$ assuming an alpha of 0.017 , an intracluster correlation of 0.01 , and an overall rate of adherence of $50 \%$. Our final sample size of 155 provides $\sim 55 \%$ power to detect the same difference under the same assumptions. Appointment adherence was defined as attendance of one or more of the recommended follow-up visits. Subjects who did not attend any appointments after the baseline appointment were consequently classified as nonadherent. The appointment adherence rates were compared among the three groups using chi-square test at a significance level of 0.05 . Poisson regression models were also applied to estimate the relative ratio of the patient navigators' interventions and the baseline individual characteristics believed to be associated with follow-up appointment adherence, including: age, gender, race, ethnicity, glaucoma diagnosis, and GDS-15 and NEI VFQ-25 scores.

\section{Secondary analyses}

We evaluated how community- and office-based interventions affected disease progression by assessing changes in clinical diagnoses. Subjects were considered to have disease progression if their diagnosis was glaucoma suspect at baseline and changed to glaucoma by their last follow-up appointment. Subjects who did not attend at least one follow-up appointment or were diagnosed with anatomically narrow angle were excluded from this analysis.

\section{Results}

A total of 155 subjects with glaucoma-related diagnoses were enrolled. The mean age ( \pm standard deviation [SD]) was $71.2( \pm 10)$ years. Table 3 summarizes subjects' baseline demographic and clinical characteristic data by groups. Subjects were predominantly female $(65.8 \%, n=102 / 155)$ and African-American $(71.6 \%, \mathrm{n}=111 / 155)$. There were more African-Americans in $\mathrm{G} 1(P<0.001)$, and more nonmarried subjects in $\mathrm{G} 2(P=0.005)$. The mean $( \pm \mathrm{SD})$ number of follow-up visits during the 1-year study period was $1.3( \pm 1.3)$ for $\mathrm{G} 1,1.6( \pm 1.3)$ for $\mathrm{G} 2$, and $1.3( \pm 1.1)$ for G3 $(P=0.48)$. Appointment adherence, defined as attendance of at least one or more follow-up visits, was $69.8 \%$ $(\mathrm{n}=37 / 53)$ for $\mathrm{G} 1,82.5 \%(\mathrm{n}=47 / 57)$ for $\mathrm{G} 2$, and $73.3 \%$ $(\mathrm{n}=33 / 45)$ for $\mathrm{G} 3,(P=0.28)$. A subanalysis was conducted to analyze whether subjects attended $\geq 2$ follow-up visits. The results are: $91.3 \%(n=21 / 23)$ of $\mathrm{G} 1,74.3 \%(n=26 / 35)$ of $\mathrm{G} 2$, and $66.7 \%(\mathrm{n}=18 / 27)$ of $\mathrm{G} 3$ attended $\geq 2$ follow-up visits $(P=0.11)$.

Overall, $73.3 \%(n=113 / 154)$ of the subjects were either single, separated, divorced, or widowed, while $54.5 \%$ $(n=84 / 154)$ reported that they lived alone at the time of their baseline visit. Regarding education completed, 77.8\% ( $n=119 / 153)$ had received at least 12 or more years of education. In all groups, $41.2 \%(n=63 / 153)$ of subjects felt that it was somewhat or very difficult to pay for basic necessities, such as food, housing, heating, and medical care; of them $88.5 \%(\mathrm{n}=52 / 63)$ were African-Americans, $11.1 \%(\mathrm{n}=7 / 63)$ Caucasians, and 6.3\% ( $\mathrm{n}=4 / 63)$ Asians.

The mean $( \pm \mathrm{SD})$ NEI VFQ-25 overall scores (on a scale of $1-100)$ were $83.98( \pm 14.75), 80.97( \pm 15.85)$, and 77.29 $( \pm 20.92)$ for $\mathrm{G} 1, \mathrm{G} 2$, and $\mathrm{G} 3$, respectively. The mean $( \pm \mathrm{SD})$ GDS-15 total scores were $2.11( \pm 3.02), 2.18( \pm 2.43)$, and 3.28 ( \pm 3.25 ) for G1, G2, and G3, respectively. Table 4 shows the factors contributing to subjects' adherence to follow-up appointments, of which age was the only statistically significant variable.

In terms of change in diagnosis from glaucoma suspect to glaucoma for subjects who attended at least one follow-up appointment at least 5 months after the baseline visit, 12 (80\%, 95\% confidence interval [59.8-100]) out of the 15 glaucoma suspect subjects remained glaucoma suspects in G1, while 19 (79.2\%, 95\% confidence interval [62.9-95.4]) out of 24 patients in $\mathrm{G} 2$, and ten $(76.9 \%, 95 \%$ confidence 
Table 3 Patients' demographic and clinical characteristics ( $n=155$ patients)

\begin{tabular}{|c|c|c|c|c|}
\hline Characteristic & Group I $(n=53)$ & Group $2(n=57)$ & Group $3(n=45)$ & $P$-value \\
\hline Age, mean $( \pm S D)$ (years) & $72.2( \pm 8.9)$ & $69.4( \pm 10.4)$ & $72.3( \pm 10.4)$ & 0.291 \\
\hline Sex, n (\%) & & & & 0.832 \\
\hline Female & $35(66.0)$ & $36(63.2)$ & $31(68.9)$ & \\
\hline Male & $18(34.0)$ & $21(36.8)$ & $14(31.1)$ & \\
\hline Race, n (\%) & & & & $<0.001$ \\
\hline African-American & 47 (88.7) & $38(66.7)$ & $26(57.8)$ & \\
\hline Asian & $5(9.4)$ & $15(26.3)$ & $4(8.9)$ & \\
\hline Caucasian & $0(0.0)$ & $3(5.3)$ & $13(28.9)$ & \\
\hline Other & I (I.9) & I (I.75) & $2(4.4)$ & \\
\hline Marital status, n (\%) & & & & 0.005 \\
\hline Married & $12(22.6)$ & $22(39.3)$ & $5(11.1)$ & \\
\hline Not married ${ }^{\mathrm{a}}$ & $4 \mid(77.4)$ & $33(58.9)$ & $39(86.7)$ & \\
\hline Other & $0(0.0)$ & $\mathrm{I}(\mathrm{I} .8)$ & I (2.2) & \\
\hline Living status, n (\%) & & & & 0.569 \\
\hline Alone & $32(60.4)$ & $29(50.9)$ & $23(52.3)$ & \\
\hline With someone else & $21(39.6)$ & $28(49.1)$ & $21(47.7)$ & \\
\hline Education, n (\%) & & & & 0.716 \\
\hline$<12$ years & $12(22.6)$ & $12(21.8)$ & $10(22.2)$ & \\
\hline $12-16$ years & $38(71.7)$ & $4 \mid(74.6)$ & $34(75.6)$ & \\
\hline$>16$ years & $3(5.7)$ & $2(3.6)$ & I (2.2) & \\
\hline Difficulty to pay for the basic & & & & 0.506 \\
\hline \multicolumn{5}{|l|}{ necessities, ${ }^{\mathrm{b}} \mathrm{n}(\%)$} \\
\hline Not difficult at all & $22(42.3)$ & $26(45.6)$ & 14 (3 I.8) & \\
\hline Not very difficult & $8(15.4)$ & $9(15.8)$ & II (25.0) & \\
\hline Somewhat difficult & $15(28.9)$ & $19(33.3)$ & $13(29.6)$ & \\
\hline Very difficult & $7(13.5)$ & $3(5.3)$ & $6(13.6)$ & \\
\hline Visual acuity, mean $( \pm S D)^{c}$ & & & & 0.110 \\
\hline Right eye & $0.19( \pm 0.17)$ & $0.33( \pm 0.58)$ & $0.49( \pm 0.76)$ & \\
\hline Left eye & $0.27( \pm 0.57)$ & $0.31( \pm 0.50)$ & $0.36( \pm 0.5 \mathrm{I})$ & \\
\hline Intraocular pressure, mean $( \pm \mathrm{SD})(\mathrm{mmHg})$ & & & & 0.899 \\
\hline Right eye & $15.7( \pm 4.0)$ & $15.3( \pm 4.3)$ & $15.3( \pm 4.2)$ & \\
\hline Left eye & $15.4( \pm 3.3)$ & $15.6( \pm 4.2)$ & $15.1( \pm 4.1)$ & \\
\hline
\end{tabular}

Notes: aSingle (never married), separated, divorced, widowed; 'Basic necessities include: food, housing, heating, and medical care; 'Logarithm of the minimum angle of resolution (logMAR).

Abbreviation: SD, standard deviation.

interval [54.0-99.8]) out of 13 subjects in G3 remained glaucoma suspects and did not show disease progression.

When disease severity was compared with appointment adherence, 57 (77\%) out of a total of 74 glaucoma suspect subjects (less severe diagnosis) attended at least one scheduled follow-up appointment, while 32 (71.1\%) out 45 glaucoma subjects (more severe diagnosis) attended their follow-up appointment(s).

\section{Discussion}

This study was a prospective, randomized, control trial to determine if the addition of a patient navigator in high-risk subjects diagnosed with glaucoma or a glaucoma-related condition (including glaucoma suspect and anatomically narrow angle) improved follow-up appointment adherence. Over the course of 1 year, 155 subjects were enrolled in this study, all of whom were diagnosed with or were suspected of a glaucoma-related eye condition in a prior community screening project. ${ }^{25,26}$ The primary outcome was adherence to follow-up eye appointments after a baseline assessment and eye examination visit. The three randomized study groups were demographically and clinically comparable, and results showed no statistically significant difference in appointment adherence rates between community- and office-based settings with and without a patient navigator at the first follow-up visit.

In the intervention groups, patient navigators addressed transportation needs and sent additional reminder (before appointment) and retention (after missed appointment) letters. It is possible that the mitigation of transportation barriers and subject forgetfulness diminished the difference between community- and office-based care. However, while the intervention groups did receive additional support, the lack of differences between the intervention and usual 
Table 4 Factors associated with appointment adherence

\begin{tabular}{|c|c|c|c|}
\hline Factors & $\begin{array}{l}\text { Relative } \\
\text { ratios }\end{array}$ & $95 \% \mathrm{Cl}$ & $P$-value \\
\hline \multicolumn{4}{|l|}{ Randomized groups ${ }^{a}$} \\
\hline Group I & 0.95 & $(0.74-1.22)$ & 0.70 \\
\hline Group 2 & 1.12 & $(0.91-1.39)$ & 0.28 \\
\hline Group 3 & 1.0 & & \\
\hline \multicolumn{4}{|l|}{ Age (years) } \\
\hline$\geq 65$ & 0.83 & $(0.70-0.98)$ & 0.03 \\
\hline$<65$ & 1.0 & & \\
\hline \multicolumn{4}{|l|}{ Sex } \\
\hline Female & 1.08 & $(0.89-1.32)$ & 0.45 \\
\hline Male & 1.0 & & \\
\hline \multicolumn{4}{|l|}{ Race } \\
\hline $\mathrm{AA}$ & 0.86 & $(0.72-1.02)$ & 0.08 \\
\hline Non-AA & 1.0 & & \\
\hline \multicolumn{4}{|l|}{ Diagnosis at baseline } \\
\hline Glaucoma & 0.94 & $(0.75-1.18)$ & 0.59 \\
\hline Narrow angle & 1.06 & $(0.87-I .3 I)$ & 0.55 \\
\hline Glaucoma suspect & 1.0 & & \\
\hline \multicolumn{4}{|l|}{ Education (years) } \\
\hline$>12$ & 0.98 & $(0.8 \mathrm{I}-\mathrm{I} .19)$ & 0.82 \\
\hline$\leq 12$ & 1.0 & & \\
\hline \multicolumn{4}{|l|}{ Marital status } \\
\hline Married & 1.03 & $(0.84-1.26)$ & 0.78 \\
\hline Not married & 1.0 & & \\
\hline \multicolumn{4}{|l|}{ Living status } \\
\hline With someone else & 1.16 & $(0.97-1.39)$ & 0.11 \\
\hline Lives alone & 1.0 & & \\
\hline \multicolumn{4}{|c|}{ Difficulty to pay for basic necessities } \\
\hline Very or somewhat & 1.02 & $(0.85-1.23)$ & 0.81 \\
\hline Not at all or not very & 1.0 & & \\
\hline \multicolumn{4}{|l|}{ NEI VFQ-25 overall score } \\
\hline Increase by I & 1.00 & $(0.99-1.01)$ & 0.78 \\
\hline \multicolumn{4}{|l|}{ GDS-15 score } \\
\hline$\geq 10$ (depression) & 0.67 & $(0.72-1.28)$ & 0.78 \\
\hline$>5$ (depressive symptoms) & 1.07 & $(0.82-I .4 I)$ & 0.62 \\
\hline$\leq 5$ (normal) & 1.0 & & \\
\hline \multicolumn{4}{|l|}{ Best corrected visual acuity } \\
\hline Increase by 0.1 logMAR & 0.99 & $(0.98-1.01)$ & 0.35 \\
\hline \multicolumn{4}{|l|}{$\begin{array}{l}\text { Eye with highest intraocular } \\
\text { pressure }\end{array}$} \\
\hline Increase by I mmHg & 0.99 & $(0.97-1.02)$ & 0.53 \\
\hline
\end{tabular}

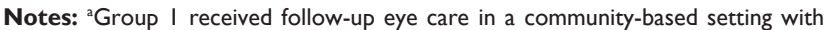
assistance from a patient navigator; Group 2 received follow-up eye care in an officebased setting with assistance from a patient navigator; Group 3 received follow-up eye care in an office-based setting without a patient navigator (usual care). Abbreviations: AA, African-American; Cl, confidence interval; GDS-I5, Geriatric Depression Scale-15; logMAR, logarithm of the minimum angle of resolution; NEI VFQ-25, National Eye Institute-Visual Function Questionnaire-25.

care groups as well as the relatively high rates of follow-up appointment adherence in all groups, particularly among the females and African-Americans, could be due to the patientcentered study design.

These patient-centered approaches included: all subjects received a reminder phone call prior to their scheduled appointment, per the standard of care protocol at Wills
Eye Hospital. There were no fees for eye examinations or laser therapy, and medication adherence education and assistance. Medication financial support was provided to all subjects, as needed. Staff members also helped all subjects with obtaining health insurance, made nonglaucoma ophthalmic referrals, and provided interpreters as needed. All subjects also received financial compensations in the form of gift cards after randomization and at the final study visit.

Several studies have indicated the need to address the lack of follow-up appointment attendance in an office-based setting among subjects diagnosed with glaucoma. ${ }^{14,15,33}$ Among these, poor follow-up adherence rates were highest among African-Americans, subjects aged 50-80 years, and those diagnosed with advanced stages of glaucoma. ${ }^{10-12,15,16}$ One of these studies included: a community-based eye screening program in Baltimore, supported by Hoffberger Family Philanthropies, which targeted a high-risk population similar to that found in our present study. ${ }^{9}$ The Hoffberger Program conducted community-based glaucoma screening examinations with a $59 \%$ rate of nonadherence to their follow-up visit. Among the most common reported reasons for lack of attendance were: no reminder letter received, forgot to come to appointment, lack of transportation, and fear of cost. Our study design addressed these barriers by providing reminder phone calls and giving free study visits to all subjects, which may explain the relative high rates of follow-up appointment adherence across all groups. The extra reminder and retention letters, along with the transportation assistance provided by patient navigators, did not appear to have made any additional impact on appointment adherence.

One secondary outcome analyzed in our study was change in clinical diagnosis from baseline to the last follow-up appointment. Glaucoma diagnosis changes (glaucoma suspect to glaucoma) were comparable among the three groups, showing no differences between patient navigator and usual care groups, or community- versus office-based sites. Moreover, despite most of the glaucoma suspect subjects maintaining the same diagnoses within 5 months of their baseline visits, eleven (21.2\%) out of 52 total glaucoma suspect subjects were diagnosed with glaucoma. This demonstrated that follow-up appointment adherence is particularly important for glaucoma suspect subjects, as early detection and treatment is vital to slowdown disease progression and prevent blindness. ${ }^{3-7,15}$

As a whole, disease severity did not correlate with an increase in follow-up eye examination appointment adherence, as suggested in previous published papers. ${ }^{9}$ Our results show that appointment adherence rates were relatively high 
and similar between all subjects diagnosed as glaucoma suspects $(77 \%, \mathrm{n}=57 / 74)$ and with glaucoma $(71.1 \%$, $n=32 / 45)$. This high rate of follow-up is unexpected since our study patients had overall high NEI VFQ-25 scores, which indicated that the self-reported, subjective visual function was relatively high among our study population. A possible explanation for this unexpected result may be due to the effect of aforementioned patient-centered study design across all groups.

Based on the relative ratios provided in Table 4, age $>65$ years may be associated with lower appointment adherence rates. This statistically significant result is contrary to previous reports that indicate younger subjects, male, minorities (especially African-Americans or Latinos), those with a less severe diagnosis or those who live far away from eye care providers are less likely to adhere to scheduled eye examination appointments. ${ }^{10}$

\section{Limitations}

In addition to the previously noted patient-centered study design, there are several limitations that may have contributed to our results and warrant discussion. All of our study subjects were recruited from and had completed the Philadelphia Glaucoma Detection and Treatment Project. Appointment adherence patterns were not analyzed in the previous study. Subjects in the current study were therefore self-selected and may not reflect the general patient population; however, they still represent a high-risk, targeted group.

In addition, all the subjects recruited were familiar with the research staff, which likely increased appointment adherence across all groups. It is well known that a robust patientprovider relationship improves eye care and follow-up appointment adherence. ${ }^{10}$ Accordingly, it is possible that a sufficiently strong research team-patient relationship had developed after the 2-year Philadelphia Glaucoma Detection and Treatment Project.

Lastly, the definition of appointment adherence has not been consistent or universally agreed upon by most researchers. We based our definition of appointment adherence, which was attendance of at least one or more scheduled follow-up appointments, on the fact that the glaucomatous conditions of our study subject population varied greatly. Actual appointment follow-up recommendations hence were often made based on clinical needs and not on study protocol guideline of returning in 6 months or 1 year. For example, some subjects were recommended to follow-up once a year, while others may have been asked to return in 1 month, especially if they had consented to receive laser therapy.
This resulted in some subjects with more scheduled appointments (the most was 6 appointments) in 1 year. Undoubtedly, if the appointment adherence definition were to change, the result could potentially vary.

Moreover, adherence was only measured in regard to appointment adherence, which is different from the common use of the term "adherence" to refer to taking prescribed medications. Adherence to glaucoma treatment (ie, prescribed eye drops) was not tracked throughout the course of this trial. According to Ung et al, patients prescribed glaucoma medications were less likely to attend their follow-up appointments. ${ }^{16}$ Glaucoma severity range of these subjects was not included in the current investigation. Further study is needed to evaluate the role of a patient navigator in subjects with varying degrees of glaucoma. Furthermore, our 1-year study period may be insufficient time to judge follow-up appointment adherence rates for certain subjects, since ongoing follow-up appointments are often required for those diagnosed with glaucoma.

\section{Conclusion}

In summary, this prospective, randomized, controlled study provides useful information about strategies to increase follow-up appointment adherence rates in a high-risk, targeted population at high-risk for glaucoma through patient navigators at community-based locations. Subjects at highrisk for glaucoma with poor access to eye care due to accessibility and personal issues, such as finances, transportation, or forgetfulness, were enrolled, monitored, and treated. The results of this study suggest a comprehensive, patientcentered approach can improve access to eye care and follow-up appointment adherence for glaucoma care in a high-risk population.

Although adherence rates to follow-up recommendations were similar between community- and office-based settings, overall adherence rates in the study were relatively high among this high-risk population, reaching close to $70 \%$ or above across all groups. We believe that this is due primarily to the fact that subjects self-selected to participate in the study, and all subjects received phone call reminders, no charge for examinations, and gift cards for participating.

\section{Acknowledgment}

Glaucoma Research Group: Christine Burns; Meskerem Divers; Jeanne Molineaux; Shayla Stratford; Nitasha Khanna; Ann P Murchison; George L Spaeth.

We thank the Glaucoma Research Group for all their help, input, and support in the process of completing this paper. 
The abstract of this paper was presented at the Association for Research in Vision and Ophthalmology (ARVO) 2016 Annual Meeting as a poster presentation with interim findings.

The findings and conclusions in this report are those of the authors and do not necessarily represent the official position of the US Centers for Disease Control and Prevention.

\section{Disclosure}

This study was funded by the Partridge Foundation with support from the US Centers for Disease Control and Prevention. The authors report no other conflicts of interest in this work.

\section{References}

1. Kingman S. Glaucoma is second leading cause of blindness globally. Bull World Health Organ. 2004;82(11):887-888.

2. Tham YC, Li X, Wong TY, Quigley HA, Aung T, Cheng CY. Global prevalence of glaucoma and projections of glaucoma burden through 2040: a systematic review and meta-analysis. Ophthalmology. 2014; 121(11):2081-2090.

3. Directors CD. Vision Problems in the United States: Recommendations for a State Public Health Response. National Association of Chronic Disease Directors; 2004.

4. Friedman DS, Wolfs RC, O'Colmain BJ, et al. Prevalence of open-angle glaucoma among adults in the United States. Arch Ophthalmol. 2004; 122(4):532-538.

5. Chen PP. Risk and risk factors for blindness from glaucoma. Curr Opin Ophthalmol. 2004;15(2):107-111.

6. Weinreb RN, Khaw PT. Primary open-angle glaucoma. Lancet. 2004; 363(9422):1711-1720.

7. Obstbaum SA, Cioffi GA, Krieglstein GK, et al. Gold standard medical therapy for glaucoma: defining the criteria identifying measures for an evidence-based analysis. Clin Ther. 2004;26(12):2102-2120.

8. Mandalos A, Bourne R, French K, Newsom W, Chang L. Shared care of patients with ocular hypertension in the community and hospital allied network glaucoma evaluation scheme (CHANGES). Eye (Lond). 2012;26(4):564-567.

9. Quigley HA, Park CK, Tracey PA, Pollack IP. Community screening for eye disease by laypersons: the Hoffberger program. Am J Ophthalmol. 2002;133(3):386-392.

10. Fudemberg SJ, Lee B, Waisbourd M, et al. Factors contributing to nonadherence to follow-up appointments in a resident glaucoma clinic versus primary eye care clinic. Patient Prefer Adherence. 2016;10:19-25.

11. Murakami Y, Lee BW, Duncan M, et al. Racial and ethnic disparities in adherence to glaucoma follow-up visits in a county hospital population. Arch Ophthalmol. 2011;129(7):872-878.

12. Lee BW, Murakami Y, Duncan MT, et al. Patient-related and systemrelated barriers to glaucoma follow-up in a county hospital population. Invest Ophthalmol Vis Sci. 2013;54(10):6542-6548.

13. Agorastos A, Skevas C, Matthaei M, et al. Depression, anxiety, and disturbed sleep in glaucoma. $J$ Neuropsychiatry Clin Neurosci. 2013; 25(3):205-213.

14. Waterman H, Brunton L, Fenerty C, Mottershead J, Richardson C, Spencer F. Adherence to ocular hypotensive therapy: patient health education needs and views on group education. Patient Prefer Adherence. 2013;7:55-63.
15. Sleath BL, Blalock SJ, Muir KW, et al. Determinants of self-reported barriers to glaucoma medicine administration and adherence: a multisite study. Ann Pharmacother. 2014;48(7):856-862.

16. Ung C, Murakami Y, Zhang E, et al. The association between compliance with recommended follow-up and glaucomatous disease severity in a county hospital population. Am J Ophthalmol. 2013;156(2):362-369.

17. Rosdahl JA, Swamy L, Stinnett S, Muir KW. Patient education preferences in ophthalmic care. Patient Prefer Adherence. 2014;8: $565-574$.

18. van Zyl T, Su Z, Zhou E, et al. Providing prescheduled appointments as a strategy for improving follow-up compliance after community-based glaucoma screening: results from an urban underserved population. J Community Health. 2015;40(1):27-33.

19. Tondee TH. Social service management of glaucoma. J Natl Med Assoc. 1943;35(6):186-191.

20. Freeman HP. The origin, evolution, and principles of patient navigation. Cancer Epidemiol Biomarkers Prev. 2012;21(10):1614-1617.

21. Freund KM, Battaglia TA, Calhoun E, et al. Impact of patient navigation on timely cancer care: the Patient Navigation Research Program. J Natl Cancer Inst. 2014;106(6):dju115.

22. Allison AL, Ishihara-Wong DD, Domingo JB, et al. Helping cancer patients across the care continuum: the navigation program at the Queen's Medical Center. Hawaii J Med Public Health. 2013;72(4):116-121.

23. Otsuki M, Eakin MN, Rand CS, et al. Adherence feedback to improve asthma outcomes among inner-city children: a randomized trial. Pediatrics. 2009;124(6):1513-1521.

24. Hryniuk W, Simpson R, McGowan A, Carter P. Patient perceptions of a comprehensive cancer navigation service. Curr Oncol. 2014;21(2): 69-76.

25. Hark L, Waisbourd M, Myers JS, et al. Improving access to eye care among persons at high-risk of glaucoma in philadelphia - design and methodology: the Philadelphia glaucoma detection and treatment project. Ophthalmic Epidemiol. 2016;23(2):122-130.

26. Waisbourd M, Pruzan NL, Johnson D, et al. The Philadelphia glaucoma detection and treatment project: detection rates and initial management. Ophthalmology. 2016;123(8):1667-1674.

27. Panel AAoOPPPG. Preferred Practice Pattern: Primary Open-Angle Glaucoma. American Academy of Ophthalmology; 2015.

28. Wu P, Xi S, Xia H, Lu H, Guo W. Survey on vision-related quality of life and self-management among patients with glaucoma. J Glaucoma. 2014;23(2):75-80.

29. Mollazadegan K, Huang J, Khadka J, et al. Cross-cultural validation of the national eye institute visual function questionnaire. $J$ Cataract Refract Surg. 2014;40(5):774-784.

30. To KG, Meuleners L, Chen HY, et al. Assessing the test-retest repeatability of the Vietnamese version of the National Eye Institute 25-item Visual Function Questionnaire among bilateral cataract patients for a Vietnamese population. Australas J Ageing. 2014;33(2): E7-E10.

31. Popescu ML, Boisjoly H, Schmaltz H, et al. Explaining the relationship between three eye diseases and depressive symptoms in older adults. Invest Ophthalmol Vis Sci. 2012;53(4):2308-2313.

32. Skalicky S, Goldberg I. Depression and quality of life in patients with glaucoma: a cross-sectional analysis using the Geriatric Depression Scale-15, assessment of function related to vision, and the Glaucoma Quality of Life-15. J Glaucoma. 2008;17(7):546-551.

33. Gray SF, Spencer IC, Spry PG, et al. The Bristol Shared Care Glaucoma Study - validity of measurements and patient satisfaction. J Public Health Med. 1997;19(4):431-436. 


\section{Publish your work in this journal}

Patient Preference and Adherence is an international, peer-reviewed, open access journal that focuses on the growing importance of patient preference and adherence throughout the therapeutic continuum. Patient satisfaction, acceptability, quality of life, compliance, persistence and their role in developing new therapeutic modalities and compounds to optimize

clinical outcomes for existing disease states are major areas of interest for the journal. This journal has been accepted for indexing on PubMed Central. The manuscript management system is completely online and includes a very quick and fair peer-review system, which is all easy to use. Visit http://www. dovepress.com/testimonials.php to read real quotes from published authors.

Submit your manuscript here: http://www.dovepress.com/patient-preference-and-adherence-journal 